\title{
Benefícios do ultrassom associado à cafeína no tratamento de lipodistrofia localizada
}

\author{
Benefits of caffeine-associated ultrasound in the treatment of localized lipodystrophy \\ Beneficios del ultrasonido asociado con cafeína en el tratamiento de la lipodistrofia localizada
}

Recebido: 30/11/2021 | Revisado: 06/12/2021 | Aceito: 08/12/2021 | Publicado: 18/12/2021

\author{
Anna Julia Xavier Guerra \\ ORCID: https://orcid.org/0000-0001-7648-2964 \\ Faculdade Independente do Nordeste, Brasil \\ E-mail: annajxavier.g@gmail.com \\ Emanuelle Nascimento do Vale Bonfim \\ ORCID: https://orcid.org/0000-0001-8872-3251 \\ Faculdade Independente do Nordeste, Brasil \\ E-mail: manunasc13@gmail.com \\ Jeane Rocha Santos \\ ORCID: https://orcid.org/0000-0002-1398-3638 \\ Faculdade Independente do Nordeste, Brasil \\ E-mail: jeane@fainor.com.br
}

\begin{abstract}
Resumo
Lipodistrofia se trata de uma disfunção ocasionada pelo acúmulo de células de gordura no tecido, que pode ser causado por diversos fatores, como hereditariedade, má postura, alimentação inadequada, dentre outros. O ultrassom terapêutico de $3 \mathrm{MHz}$ é um equipamento que se mostra bastante eficaz para o tratamento de disfunções estéticas, dentre elas o acúmulo irregular de gordura. Trata-se de uma revisão de literatura cujo objetivo geral foi avaliar os efeitos do ultrassom terapêutico associado à cafeína para o tratamento da lipodistrofia localizada. Este estudo consistiu em levantamentos bibliográficos nas bases eletrônicas como: a Scientific Eletronic Library Online - Scielo, Bireme, e Google acadêmico e LILACS (Literatura científica e técnica da América Latina e Caribe), a seleção dos artigos foi feita segundo a leitura da revisão e da introdução dos mesmos. Após seleção e análise desses materiais foi identificado a eficácia do ultrassom para o tratamento da lipodistrofia localizada, devido seu efeito térmico e mecânico agitando assim as moléculas, e a cafeína com efeito lipolítico. Conclui-se que as literaturas existentes, há diversos materiais que comprovam a eficácia do US e cafeína, a associação de ambos, pode promover respostas bastante satisfatórias no tratamento dessa disfunção estética.
\end{abstract}

Palavras-chave: Ultrassom; Lipodistrofia; Cafeína.

\begin{abstract}
Lipodystrophy is a dysfunction caused by the accumulation of fat cells in the tissue, which can be caused by several factors, such as heredity, bad posture, improper diet, among others. The $3 \mathrm{MHz}$ therapeutic ultrasound is an equipment that shows to be very effective for the treatment of aesthetic dysfunctions, among them the irregular accumulation of fat. This is a literature review whose general objective was to evaluate the effects of therapeutic ultrasound associated with caffeine for the treatment of localized lipodystrophy. This study consisted of bibliographic research in electronic databases such as: Scientific Eletronic Library Online - Scielo, Bireme, and Google academic and LILACS (Scientific and Technical Literature from Latin America and the Caribbean). After selection and analysis of these materials it was identified the effectiveness of the ultrasound for the treatment of localized lipodystrophy, due to its thermal and mechanical effect thus agitating the molecules, and the caffeine with lipolytic effect. It is concluded that the existing literatures, there are several materials that prove the effectiveness of the US and caffeine, the association of both, can promote very satisfactory responses in the treatment of this aesthetic dysfunction. Keywords: Ultrasound; Lipodystrophy; Caffeine.
\end{abstract}

\section{Resumen}

La lipodistrofia es una disfunción causada por la acumulación de células grasas en el tejido, que puede ser causada por diversos factores, como la herencia, la mala postura, la dieta inadecuada, entre otros. El ultrasonido terapéutico de 3 $\mathrm{MHz}$ es un equipo que se muestra muy eficaz para el tratamiento de disfunciones estéticas, entre ellas la acumulación irregular de grasa. Se trata de una revisión bibliográfica cuyo objetivo general fue evaluar los efectos del ultrasonido terapéutico asociado a la cafeína para el tratamiento de la lipodistrofia localizada. Este estudio consistió en relevamientos bibliográficos en bases de datos electrónicas como: Scientific Eletronic Library Online - Scielo, Bireme, y Google académico y LILACS (Literatura Científica y Técnica de América Latina y el Caribe), la selección de los artículos se realizó de acuerdo a la lectura de la revisión y de su introducción. Tras la selección y el análisis de estos materiales se identificó la eficacia de los ultrasonidos para el tratamiento de la lipodistrofia localizada, debido a su efecto térmico y mecánico que agita las moléculas, y de la cafeína con efecto lipolítico. Se concluye que en la 
literatura existente, hay varios materiales que prueban la eficacia del US y la cafeína, la asociación de ambos, puede promover respuestas muy satisfactorias en el tratamiento de esta disfunción estética.

Palabras clave: Ultrasonido; Lipodistrofia; Cafeína.

\section{Introdução}

O acúmulo irregular de tecido adiposo em determinadas regiões do corpo é denominado Lipodistrofia localizada. Nem sempre está relacionada com um quadro de obesidade e impacta negativamente na autoestima dos indivíduos (Bouchard, 2003). Segundo Pereira (2007), a lipodistrofia localizada tem a característica de permanecer mesmo que o indivíduo emagreça. Este acúmulo pode ser determinado comumente pela herança genética. E a depender da região onde o indivíduo mais acumula, o seu biotipo corporal pode ser classificado em: Androide (acumula mais em região abdominal) e Ginóide (quando o acúmulo é maior nas pernas e no quadril) (Agne, 2009).

Machado et al. (2017) descreve que o acúmulo de gordura localizada pode estar relacionado com vários fatores, dentre eles: quantidade e localização das células adiposas, idade, sexo, alimentação e sedentarismo. E Borges (2006), afirma que a gordura localizada está associada a uma desaceleração do metabolismo, ocasionando um acúmulo maior. É válido ressaltar que a gordura é fundamental para o corpo humano, pois é responsável pelo fornecimento de energia através das calorias ingeridas pelo indivíduo, irá regular a temperatura corporal e proteger os órgãos, regiões palmares e plantares (Borges, 2006).

De acordo com Costa et al. (2012), para instalação de um tratamento adequado para a Lipodistrofia localizada podese empregar o uso de cosméticos que contenham ativos específicos e que possam estimular a lipólise, como a cafeína. E, ainda segundo Borges (2010) recursos eletroterapêuticos são eficientes e o ultrassom é um deles, pois é capaz de promover lipólise, neovascularização e de aumentar o metabolismo.

Leonardi (2008) acredita que os ativos da cosmetologia utilizados, trazem boas respostas aos tratamentos estéticos, dentre eles, o de lipodistrofia localizada. Eles têm diferentes funcionalidades, podendo atuar como lipolíticos, e dificultando a lipogênese (armazenamento de gordura). Assim, a cafeína é um ativo que vem sendo bastante utilizado, pelo seu efeito lipolítico, promovendo assim a quebra dos triglicerídeos, o que acaba influenciando na aparência e na textura da pele. Além disso, pode ainda estimular a produção de fibroblastos, células responsáveis pela produção de colágeno e elastina, melhorando assim o tônus muscular (Magalhães \& Camargo \& Higuchi, 2013).

Um dos equipamentos mais utilizados para o tratamento da lipodistrofia localizada é o ultrassom de alta potência, pois é considerado um recurso eletroterápico não invasivo e de fácil aplicação, se mostrando bastante eficaz por promover a lipólise (Machado, 2011). Segundo Borges (2016), para que isso ocorra é necessário que o aparelho receba energia por um circuito elétrico que é convertida em agitações transformando a energia elétrica em mecânica. Na estética se utiliza o ultrassom de $3 \mathrm{MHz}$ que consegue alcançar a tela subcutânea. Devido a sua ação térmica ou mecânica, possui boa resposta em diversos tratamentos, facilitando a circulação de fluidos, contribuindo para a permeação de ativos na epiderme e melhorando oxigenação e a nutrição (Lacrimant et al, 2014).

Frente ao exposto, esta pesquisa apresenta como objetivo principal avaliar os benefícios do uso do ultrassom terapêutico associado à cafeína no tratamento da lipodistrofia localizada.

\section{Metodologia}

Foi realizada uma revisão de literatura, que de acordo com Reis (2009) consiste em compreender o tema pesquisado de forma abrangente, através das literaturas já existente, para aprofundar na temática escolhida. Trata-se de uma pesquisa descritiva exploratória, que segundo Gil (2007), estuda um tema pouco abordado e tem como objetivo torná-lo mais explícito. A pesquisa foi realizada, nas bases eletrônicas: a Scientific Eletronic Library Online - Scielo, Bireme, e Google acadêmico e LILACS (Literatura científica e técnica da América Latina e Caribe, através dos descritores: cafeína, lipodistrofia, ultrassom, artigos científicos que abordaram a temática que foi estudada, sendo revisão de literatura ou estudo de caso. A seleção dos 
artigos foi feita segundo a leitura da revisão e da introdução dos mesmos. Como critérios de inclusão foram adotados artigos que abordaram a temática em questão e artigos publicados entre os anos de 2004 a 2020. Como critérios de exclusão: não foram selecionados artigos que não tinham ligação com o tema. A análise dos dados foi realizada através de uma análise descritiva e comparativa dos dados obtidos sobre a temática abordada. O estudo seguiu os aspectos éticos dispostos na Lei de Direitos Autorais: Lei número 9.610, de fevereiro de 1998, assegurando que as literaturas que foram utilizadas no estudo foram referenciadas corretamente, evitando assim, cópias e plágios.

\section{Resultados e Discussão}

Inicialmente foram selecionados 10 artigos, destes, 4 foram descartados por não se enquadrarem totalmente nos critérios de inclusão e exclusão supracitados. Sendo assim, a amostra do estudo foi composta por 6 artigos, publicados entre 2004 a 2020, cujos resultados desvelavam os benefícios do uso do ultrassom terapêutico associado à cafeína no tratamento da lipodistrofia localizada. Realizou-se a criação de um quadro que possibilitou organizar os dados dos artigos em: autor, tema, objetivo, métodos, resultados, e ano de publicação, conforme segue no Quadro 1 abaixo:

Quadro 1 - Artigos selecionados segundo título, autorlano, objetivos, métodos, resultados. Vitória da Conquista, Bahia, Brasil. 2021.

\begin{tabular}{|c|c|c|c|c|}
\hline Título & Autor $\backslash$ Ano & Objetivos & Métodos & Resultados \\
\hline $\begin{array}{l}\text { A atuação da } \\
\text { cafeína } \\
\text { biovetorizada e do } \\
\text { ultrassom no } \\
\text { tratamento da } \\
\text { lipodistrofia } \\
\text { localizada na região } \\
\text { abdominal: revisão } \\
\text { literária }\end{array}$ & $\begin{array}{l}\text { Ana Paula } \\
\text { Alves de } \\
\text { OliveirA, } \\
\text { Karina da } \\
\text { Silva PIRES, } \\
\text { Juliana } \\
\text { Aparecida } \\
\text { Ramiro } \\
\text { Moreira. } \\
\text { (2018) }\end{array}$ & $\begin{array}{l}\text { Verificar a atuação da cafeína } \\
\text { biovetorizada, os benefícios } \\
\text { coadjuvantes de seus ativos e } \\
\text { o prolongamento desses } \\
\text { resultados. }\end{array}$ & $\begin{array}{l}\text { Foi realizado } \\
\text { levantamento de } \\
\text { temas } \\
\text { relacionados à } \\
\text { ação da cafeína e } \\
\text { do ultrassom não } \\
\text { focado e de baixa } \\
\text { frequência }\end{array}$ & $\begin{array}{l}\text { Os resultados apontaram que: a emulsão } \\
\text { com cafeína apresentou redução de } 17 \% \\
\text { no diâmetro em comparação com o } \\
\text { controle; a emulsão com cafeína + } \\
\text { benzoato de sódio não apresentou } \\
\text { alteração no diâmetro das células; e a } \\
\text { emulsão com SAC apresentou redução de } \\
16 \% \text { no diâmetro e redução de } 32 \% \text { no } \\
\text { número de células em comparação com o } \\
\text { controle de células. }\end{array}$ \\
\hline $\begin{array}{l}\text { Uso da fonoforese } \\
\text { com transcutol, } \\
\text { cafeína, carnitina } 1 \\
\text { base e gel de } \\
\text { carbopol no } \\
\text { tratamento da } \\
\text { lipodistrofia } \\
\text { localizada }\end{array}$ & $\begin{array}{l}\text { Daiane } \\
\text { Gomes de } \\
\text { Godoy, } \\
\text { Juliana } \\
\text { Carvalho et al. } \\
(2016)\end{array}$ & $\begin{array}{l}\text { O objetivo deste estudo foi } \\
\text { identificar os efeitos da } \\
\text { fonoforese na redução de } \\
\text { pregas cutâneas e perimetria } \\
\text { de cintura. }\end{array}$ & $\begin{array}{l}\text { A amostra foi } \\
\text { composta por dez } \\
\text { mulheres, sendo } \\
\text { alocadas em dois } \\
\text { grupos: controle e } \\
\text { estudo, sendo } \\
\text { submetidas à um } \\
\text { processo de } \\
\text { intervenção, } \\
\text { totalizando doze } \\
\text { sessões sob uma } \\
\text { frequência de duas } \\
\text { vezes por semana. } \\
\text { O grupo estudo } \\
\text { foi submetido à } \\
\text { intervenção com } \\
\text { fonoforese } \\
\text { (ultrassom+ativos) } \\
\text { e o grupo controle } \\
\text { recebeu o UST } \\
\text { isolado. }\end{array}$ & $\begin{array}{l}\text { A média de idade dos dez sujeitos foi } 23 \\
\pm 1,49 \text { anos. Os dados indicaram } \\
\text { probabilidades de efeito superior no } \\
\text { grupo estudo, o qual recebeu a } \\
\text { fonoforese, pois foi constatado reduções } \\
\text { de adipometria (região supra ilíaca direita } \\
\text { e esquerda). }\end{array}$ \\
\hline
\end{tabular}


Research, Society and Development, v. 10, n. 16, e489101624139, 2021

(CC BY 4.0) | ISSN 2525-3409 | DOI: http://dx.doi.org/10.33448/rsd-v10i16.24139

\begin{tabular}{|c|c|c|c|c|}
\hline $\begin{array}{l}\text { Efeito do ultrassom } \\
\text { terapêutico na } \\
\text { comparação das } \\
\text { técnicas direta e } \\
\text { fonoforese com gel } \\
\text { de cafeína no } \\
\text { tratamento do fibro } \\
\text { edema geloide }\end{array}$ & $\begin{array}{l}\text { Kelly Bispo } \\
\text { da Cruz, Aline } \\
\text { Fernanda } \\
\text { Perez } \\
\text { Machado et } \\
\text { al. (2015) }\end{array}$ & $\begin{array}{l}\text { Verificar o efeito do } \\
\text { ultrassom terapêutico na } \\
\text { comparação das técnicas } \\
\text { direta e fonoforese com gel } \\
\text { de cafeína no tratamento de } \\
\text { fibro edema geloide }\end{array}$ & 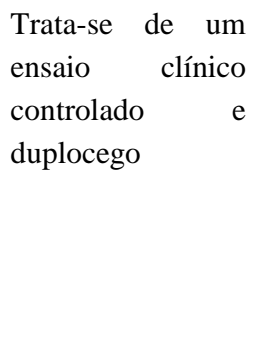 & $\begin{array}{l}\text { Observou-se que ambas as técnicas direta } \\
\text { e a fonoforese com cafeína foram eficazes } \\
\text { na diminuição do grau do FEG e no } \\
\text { aumento da satisfação corporal das } \\
\text { voluntárias na comparação pré e pós- } \\
\text { intervenção. }\end{array}$ \\
\hline $\begin{array}{lr}\text { Avaliação } & \text { da } \\
\text { permeação e } & \text { da } \\
\text { retenção da cafeína } \\
\text { associadas } \\
\text { ultrassom } \\
\text { terapêutico. }\end{array}$ & $\begin{array}{l}\text { João Alberto } \\
\text { Tassinary } \\
\text {,Laís } \\
\text { Bresciani et } \\
\text { al. (2015) }\end{array}$ & $\begin{array}{l}\text { Avaliar a permeação e a } \\
\text { retenção in vitro do princípio } \\
\text { ativo cafeína, quando } \\
\text { adicionado a hidrogel, com e } \\
\text { sem aplicação do US } \\
\text { terapêutico. }\end{array}$ & $\begin{array}{l}\text { Realizou-se } \\
\text { estudo de caráter } \\
\text { qualitativo e } \\
\text { experimental. }\end{array}$ & $\begin{array}{l}\text { Verificou-se que, nas análises com a } \\
\text { utilização do US terapêutico, há um } \\
\text { aumento de permeação quando } \\
\text { comparado com as análises sem aplicação } \\
\text { do US. }\end{array}$ \\
\hline $\begin{array}{lr}\text { Avaliação } & \text { dos } \\
\text { efeitos do ultrassom } & \\
\text { terapêutico } & \text { sobre a } \\
\text { cafeína } & \text { e } \\
\text { verificação } & \text { da } \\
\text { liberação } & \text { em } \\
\text { sistema de } & \text { difusão } \\
\text { vertical }\end{array}$ & $\begin{array}{l}\text { João Alberto } \\
\text { Tassinary, } \\
\text { Paula } \\
\text { Bianchetti e } \\
\text { Claudete } \\
\text { Rempel } \\
\text { (2011) }\end{array}$ & $\begin{array}{l}\text { O objetivo do presente } \\
\text { trabalho foi realizar estudos } \\
\text { da liberação da cafeína, } \\
\text { quando adicionada a um gel } \\
\text { transmissor, com e sem a } \\
\text { aplicação do US terapêutico, } \\
\text { além de avaliar, por meio } \\
\text { eletroquímico, possíveis } \\
\text { reações de oxidação ocorridas } \\
\text { após a aplicação deste. }\end{array}$ & $\begin{array}{l}\text { Foi montado um } \\
\text { sistema sobre uma } \\
\text { mesa agitadora. }\end{array}$ & $\begin{array}{l}\text { Os resultados sugerem uma maior } \\
\text { liberação da cafeína quando associada à } \\
\text { onda sônica terapêutica, ou seja, o US se } \\
\text { apresentou como facilitador no processo } \\
\text { de liberação da cafeína para o meio. }\end{array}$ \\
\hline 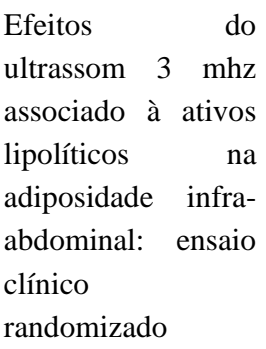 & $\begin{array}{l}\text { Janaína } \\
\text { Manhães } \\
\text { Chartuni et al. } \\
\text { (2011) }\end{array}$ & $\begin{array}{l}\text { O presente estudo objetivou } \\
\text { avaliar os efeitos do } \\
\text { ultrassom } 3 \mathrm{MHZ} \text { com ativos } \\
\text { lipolíticos para redução da } \\
\text { gordura localizada na região } \\
\text { infra-abdominal }\end{array}$ & $\begin{array}{l}\text { Um ensaio clínico } \\
\text { randomizado } \\
\text { experimental, } \\
\text { duplo cego, do } \\
\text { tipo longitudinal } \\
\text { intervencionista. }\end{array}$ & $\begin{array}{l}\text { Os resultados mostraram que houve } \\
\text { redução pós-tratamento da adipometria e } \\
\text { da perimetria infraabdominal em todos os } \\
\text { grupos quando comparados aos valores } \\
\text { pré-tratamento } \quad \text { (p0.05). O grupo } \\
\text { US+Ativos apresentou diferença na } \\
\text { adipometria quando comparado ao CTRL } \\
\text { (p<0.05 }\end{array}$ \\
\hline
\end{tabular}

Fonte: Autores.

Um dos principais recursos terapêuticos utilizados para gordura localizada é o ultrassom, recurso que é capaz de reduzir a adiposidade localizada (Costa \& Mejia, 2013). De acordo com Gonçalves et al (2005), os efeitos mecânicos do ultrassom (US) nos adipócitos são: aumento da atividade metabólica celular e a liberação dos lipídios da membrana celular e de seu interior, principalmente do ácido graxo e do glicerol. A utilização do Ultrassom terapêutico de $3 \mathrm{MHz}$, no modo contínuo, é capaz de tratar a adiposidade infra-abdominal, tanto se usando isoladamente ou quando em associação à ativos lipolíticos (Chartuni, 2011). De acordo com Krupek \& Mareze-da-costa (2012), dentre as diversas metilxantinas que atuam no tecido adiposo, destaca-se a cafeína, por possuir o poder de induzir lipólise, através da inibição da fosfodiesterase e aumento da adenosina monofosfato cíclica.

Em estudo realizado por Cruz et al. (2015), as 16 voluntárias foram divididas em dois grupos para avaliar o efeito do ultrassom aplicado de forma direta no local e com a associação de ativo (cafeína). Em um grupo, o ultrassom foi aplicado sem nenhum tipo de associação, já o outro recebeu a aplicação do ultrassom associado a um gel contendo cafeína. A aplicação do ultrassom associado ao gel com cafeína mostrou-se mais eficiente, reduzindo de forma significativa a espessura do tecido tratado e demonstrando respostas satisfatórias na diminuição da FEG, porém para os autores os resultados esperados era uma redução mais significativa. Além disso, houve uma melhora da satisfação corporal pela percepção das próprias voluntárias (em 
relação aos resultados pré e pós procedimento). Concluiu-se que tanto a técnica direta, quanto com fonoforese com ativos, se mostraram eficazes no tratamento da FEG.

Segundo Bessada et al. (2018) \& Torkaska (2018) a fisiopatologia do FEG, pode ser caracterizada por diversos fatores, dentre eles o aumento da camada dos adipócitos. A cafeína por ter princípio ativo lipolítico, é uma substância utilizada no tratamento dessa condição, promovendo redução da camada adipócita. A cafeína irá promover a hidrolise dos triacilgliceróis (reserva de gordura) que são responsáveis pelo armazenamento de energia. Dessa forma, com a ação desse ativo, esses índices de armazenamento serão reduzidos.

A realização da pesquisa de Godoy et al. (2016) tinha como objetivo principal analisar o efeito da fonoforese associada a alguns ativos lipolíticos, dentre eles a cafeína. Para a realização os critérios de inclusão foram não fazer uso de contraceptivos, e possuir um IMC entre 25 a $30 \mathrm{~kg} / \mathrm{cm}^{2}$. Houve divisão de grupos, cada um contendo 5 pessoas, o qual um utilizava a técnica fonoforese, os demais aplicavam ultrassom diretamente, ambos totalizaram 12 sessões. Ao término, foi comprovado que a fonoforese associada aos ativos utilizados apresentou eficácia, reduzindo assim o tecido adiposo, sendo superior ao ultrassom aplicado sem nenhuma associação.

Segundo Quessada et al. (2020) o gel de cafeína sem associação e associado a iontoforese, são eficazes na diminuição da espessura do tecido em mulheres com Lipodistrofia ginóide após aplicação de 10 sessões.

Tassinary et al. (2015) realizaram uma pesquisa cujo objetivo principal era verificar a retenção e permeação da cafeína com e sem o uso do ultrassom. Para tal, foram preparadas amostras contendo o ativo cafeína a uma concentração de $5 \%$, sendo adicionadas a gel condutor. Assim, utilizou-se biomembranas de pele de cobra pelo fato de serem semelhantes ao estrato córneo humano, com e sem o uso do ultrassom. Concluiu-se que com o uso do ultrassom se verificou aumento da permeação da cafeína.

Para a realização de uma pesquisa Chartuni et al. (2011) selecionou um grupo de mulheres com faixa etária entre 18 e 30 anos, totalizando 27 pessoas, que não praticavam atividade física, eram saudáveis e faziam uso medicamentoso de contraceptivos. O objetivo era verificar os efeitos do ultrassom terapêutico de $3 \mathrm{MHz}$ no modo contínuo, associado a ativos lipolíticos. Para a coleta de dados, elas foram divididas em 3 grupos, totalizando 12 sessões que eram realizadas três vezes por semana, um grupo utilizava o US com gel sem ativos, outro o US com ativos, por fim o outro grupo no modo contínuo desligado. Dessa forma, o estudo não encontrou dados que favoreçam o uso do ultrassom associado a ativos.

Em estudo observacional feito por Loebens \& Bianchetti (2019) o uso do ultrassom associado à massagem modeladora com um creme contendo, dentre outros ativos, a cafeína mostrou-se mais eficaz no tratamento da FEG do que o ultrassom isolado.

Oliveira et al. (2018) realizaram uma revisão de literatura que consistiu em analisar a eficácia do ultrassom não focado e de baixa frequência. Ao término do estudo, constatou-se que as técnicas utilizadas para tratamento da lipodistrofia realizadas em clínicas e consultórios tem mostrado eficácia. O levantamento comprovou a eficácia do ativo cafeína juntamente com o US, promovendo a redução do tecido adiposo. Os autores ainda concluíram que a ação do ultrassom se dá através da cavitação e do seu efeito térmico, alterando assim a permeabilidade dessas células de gordura, que por fim facilitará a ação da cafeína, que por sua vez possui efeito lipolítico.

É válido ressaltar que o tratamento mais eficaz é o preventivo, isso se dá pela prática de hábitos saudáveis, como alimentação, atividade física, com o intuito de controlar os fatores que causam lipodistrofia localizada. A adoção dessas práticas, irá influenciar diretamente no resultado do tratamento utilizado (Castoldini et al., 2017).

\section{Conclusão}

Após a realização desta pesquisa, nas fontes de dados mencionadas anteriormente, ficou evidente a eficácia do Ultrassom e do ativo cafeína para o tratamento da lipodistrofia localizada. O US é um eletroterápico bastante utilizado devido 
seus resultados satisfatórios e sua fácil aplicação, sendo indolor e com poucas restrições, o que favorece a aplicação em um grande número de indivíduos. Já a cafeína, vem sendo um ativo que nos últimos tempos está bastante em evidência, isso se deve ao seu efeito lipolítico, atuando diretamente na célula adipocitária. Desse modo, o Ultrassom associado a cafeína são bastante eficazes, pois com o aquecimento emitido pelo aparelho haverá aumento da energia das moléculas do ativo, melhorando a circulação, facilitando assim a sua absorção.

Acredita-se que este estudo irá contribuir com as próximas pesquisas a serem realizadas, pois mostrou através de fontes de dados a eficácia do ultrassom e da cafeína para o tratamento da Lipodistrofia localizada. Devido aos poucos trabalhos associando as duas propostas de tratamento, ressalta-se importância da realização de pesquisas que ratifiquem as terapias associadas e sua eficácia para esse tratamento.

Sugere-se também novos estudos acerca do tema que apresentem os números de sessões adequadas do ultrassom associado a cafeína no tratamento da gordura localizada. Além disso, que estes estudos possam trazer informações acerca da parametrização dos aparelhos.

\section{Referências}

Agne. (2009). Eu sei eletroterapia. Palotti.

Alves de Oliveira, A. P., da Silva Pires, K., \& Ramiro Moreira, J. A. (2018). A atuação da cafeína biovetorizada e do ultrassom no tratamento da lipodistrofia localizada na região abdominal: revisão literária. Medicina e Saúde, 1(1), 47-60.

Bessada, S. M., C. Alves, R., Oliveira, P., Beatriz, M. Coffee, Silverskin: A review on potential cosmetic applications. Cosmetics. $2018 ; 5(1): 5$.

Bispo da Cruz, K., Perez, Machado, A. F., Saikali, Farcic, T., Mutti, Tacani, P., Eduardo Tacani, R., Fagioli Bordello Masson, I., Schiavianto Baldan, C., \& Eloin Liebano, R. (2015). Efeito do ultrassom terapêutico na comparação das técnicas direta e fonoforese com gel de cafeína no tratamento do fibro edema geloide. J Health Sci Inst., 33(3), 259-263

Borges, F. S. (2010). Dermatofuncional modalidades terapêuticas nas disfunções estéticas (3ª ed.). Phorte.

Borges, F. S., \& Scorza, F. A. (2016). Terapêutica em estética: conceitos e técnicas. Phorte

Bouchard, C. (2003). Atividade Física e Obesidade. Manoele

Castoldini, A. P. (2017). Tratamento de lipodistrofia localizada abdominal: Estudo de caso. E da Univates.

Carvalho, C. R. Estudo do perfil do profissional e da formação acadêmica do Tecnólogo em Estética: Estudo de caso. [S. l.]: Dissertação (Mestrado em Educação)., 2009.

Chartuni, J. M. Efeitos do Ultrassom 3MHz Associado à Ativos Lipolíticos na Adiposidade Infra-Abdominal: Ensaio Clínico Randomizado. Perspectiva Online [online]. v1, n1, p. 79-90, 2011.

Costa, R., Silva, G., Limana, M.D, \& Garcez, V. F. (2012). Estudo comparativo dos efeitos da terapia combinada Manthus x Heccus no tratamento de gordura localizada na região abdominal. ( $4^{\mathrm{a}}$ ed.). Mostra interna de trabalhos de iniciação científica.

Costa, Priscila Santos; Mejia, Dayana Priscila Maia. Efeitos fisiológicos da endermoterapia Efeitos fisiológicos da endermoterapia combinados a massagem modeladora no tratamento de gordura localizada na região do abdômen. Pós-graduação (Fisioterapia Dermato - Funcional), Faculdade Cambury, 2013.

Forti Quessada, Alana Roberta et al. Effect of caffeine gel and caffeine gel associated with iontophoresis in women gynoidlipodystrophy: A pilot randomized trial. Research, Society and Development, v. 10, n. 4, p. 1-11, 2021.

Gonçalves AL., Filho AA., Menezes H. Estudo comparativo da atividade antimicrobiana de extratos de algumas árvores nativas. Arq Inst Biol 3: 353-358, 2005 .

Krupek T.; Mareze-Da-Costa C. E. Mecanismo de ação de compostos utilizados na cosmética para o tratamento da gordura localizada e da celulite. Revista Saúde e Pesquisa, v. 5, n. 3, p. 555-566, set./dez. 2012.

Lacrimant, L. M., Vanconcelos, M. G., \& Perez, E. (2014). Curso didático de estética: volume 2 (2ª ed.). Yends. Leonardi, G. R. (2008). Cosmetologia Aplicada (2a ed.). Santa Isabel.

Loebens NL., Bianchetti P. Uso do Ultrassom terapêutico associado a massagem modeladora com creme lipotérmico para o tratamento de celulite. 2019. 1-72. Trabalho de conclusão de curso (Graduação em Estética e Cosmética) - Universidade de Santa Cruz do Sul, Santa Cruz do Sul, 2019.

Machado, G. C. e.a. (2011). Análise dos efeitos do ultrassom terapêutico e da eletrolipoforese nas alterações decorrentes do fibro edema geloide. Fisioter.Mov, 24(3), 471-479.

Machado, A. T. O. M. (2017). Benefícios da Massagem Modeladora na Lipodistrofia Localizada. Revista Multidisciplinar e de Psicologia, 11(35), 1-12. 
Research, Society and Development, v. 10, n. 16, e489101624139, 2021

(CC BY 4.0) | ISSN 2525-3409 | DOI: http://dx.doi.org/10.33448/rsd-v10i16.24139

Magalhães, B. H., Camargo, M. F., \& Higuchi, C. T. (2013). Indicação de uso de espécies vegetais para tratamento da celulite com fins cosméticos. InterfacEHS-Revista de Saúde, Meio Ambiente e Sustentabilidade, 8(3).

Manhães Chartuni, J., Santos Sossai, L., \& Gomes Teixeira, C. (2011). Efeitos do ultrassom 3 mhz associado á ativos lipolíticos na adiposidade infraabdominal: ensaio clínico randomizado. Perspectivas online, 1(1), 79- 91.

Pereira, F. (2007). Eletroterapia sem mistérios: aplicações em estética facial e corporal. Rubio.

Santos Borges, F. (2006). Modalidades terapêuticas nas disfunções estéticas: dermato-funcional. Phorte

Tassinary, J. A., Bresciani, L., Bianchetti, P., Rempel, C., Schmitt, B., \& Stulp, S. (2015). Avaliação da permeção e da retenção da cafeína associadas ao ultrassom terapêutico. Revista destaques acadêmicos, 7(3), 175-181.

Torkaska, Kamila. Cellulite: a cosmetic or system icissue?Contemporary views on the etiopathogenesis of cellulite. Advances In Dermatology And Allergology. 2018. 